\title{
PRODUÇÃO DE BIODIESEL UTILIZANDO ÓLEO DE SOJA DESCARTADO POR ESTABELECIMENTO COMERCIAL ALOCADO NO IFES, CAMPUS CACHOEIRO DE ITAPEMIRIM-ES
}

\author{
BIODIESEL PRODUCTION USING SODIUM OIL DISCOVERED BY \\ COMMERCIAL ESTABLISHMENT ALLOCATED IN IFES, CAMPUS \\ CACHOEIRO OF ITAPEMIRIM-ES
}

\author{
Fabielle Castelan Marques ${ }^{1 *}$ \\ Ingrid Larissa Alves ${ }^{2}$ \\ Edmundo Rodrigues Junior ${ }^{3}$ \\ Paulo Jose Pereira de Oliveira ${ }^{4}$ \\ Bruno Fazolo Repossi ${ }^{5}$
}

\begin{abstract}
${ }^{1}$ Instituto Federal do Espírito Santo - Campus Cachoeiro de Itapemirim. E-mail: castelan@gmail.com. ${ }^{2}$ Instituto Federal do Espírito Santo - Campus Cachoeiro de Itapemirim. E-mail: ingridlarissa.alves@ gmail.com.

${ }^{3}$ Instituto Federal do Espírito Santo - Campus Cachoeiro de Itapemirim. E-mail: edmundor@ifes.edu.br. ${ }^{4}$ Instituto Federal do Espírito Santo - Campus Cachoeiro de Itapemirim. E-mail: paulojoseo@ifes.edu.br. ${ }^{5}$ Instituto Federal do Espírito Santo - Campus Cachoeiro de Itapemirim. E-mail: bruno.repossi@ifes.edu.br.

*Autor para correspondência: castelan@gmail.com.
\end{abstract}

Artigo submetido em 13/06/2019, aceito em 16/10/2019 e publicado em 23/12/2019.

Resumo: A maior parte de toda energia consumida no mundo provém do petróleo, do carvão e do gás natural. Essas fontes são limitadas e com previsão de esgotamento nas próximas décadas, portanto, a busca por fontes alternativas de energia é de suma importância, na mitigação dos efeitos ambientais causados pelos combustíveis fósseis, bem como flutuações de preços do petróleo. Uma alternativa possível ao combustível fóssil é a produção de monoalquil éster de ácidos graxos de cadeia longa através de óleos de origem vegetal, os quais podem ser denominados de biodiesel. O presente artigo tem como objetivo, produzir biodiesel por reação de transesterificação, utilizando o óleo de soja usado para uma possível aplicação na indústria local, diminuindo assim a emissão de resíduos no Rio Itapemirim, e do consumo de combustíveis fósseis. O material de partida, bem como o biodiesel obtido pela reação de transesterificação foi analisado em seus parâmetros mais importantes tais como: densidade, viscosidade, índice de acidez, índice de iodo e índice de saponificação e espectroscopia na região do UV-Vis, segundo metodologia preconizada na literatura. $\mathrm{O}$ rendimento da reação foi de $84,71 \%$ para o biodiesel proveniente do óleo in natura e $81,39 \%$ no biodiesel proveniente do óleo residual. Os dados físico-químicos obtidos no material de partida bem como no biodiesel resultante mostraram uma boa viabilidade na produção do combustível em escala piloto ou em escala industrial, porém, consideramos que o projeto se apresenta como sugestão para diminuição da poluição do Rio Itapemirim em pelo menos um dos parâmetros, no entanto, entendemos que ainda é necessário um aprofundamento na otimização da produção do biodiesel

Palavras-chave: Biodisel; óleo de soja; resíduo; transesterificação. 


\begin{abstract}
Most of consumed energy in the world comes from oil, coal and natural gas. These sources are limited and expected to deplete in the coming decades, so the search for alternative sources of energy is of paramount importance in mitigating the environmental effects caused by fossil fuels, as well as fluctuations in oil prices. A possible alternative to fossil fuel is the production of long chain fatty acid monoalkyl ester through oils of plant origin, which may be called biodiesel. This project aims to produce biodiesel by transesterification reaction, using the used soybean oil used for a possible application in the local industry, thus waste emission reducing in the Itapemirim River, and the consumption of fossil fuels. Starting material as well as the biodiesel obtained by the transesterification reaction were analyzed in its most important parameters such as density, viscosity, acidity index, iodine index and saponification index and UV-Vis spectroscopy according to the methodology recommended in the literature. The reaction yield was $84.71 \%$ for biodiesel from fresh oil and $81.39 \%$ for biodiesel from residual oil. The physicochemical data obtained in the starting material as well as in the resulting biodiesel showed a good viability in the production of fuel in pilot scale or in industrial scale, however, we consider that the project is presented as a suggestion to Itapemirim River pollution reduce in at least. At least one of the parameters, however, we understand that further deepening of the optimization of biodiesel production is still needed.
\end{abstract}

Keywords: biodiesel, soybean oil, residue, transesterification.

\section{INTRODUÇÃO}

Combustíveis a diesel são de vital importância no setor econômico de um país em desenvolvimento. A alta demanda de energia, no mundo industrializado e no setor doméstico, a instabilidade nos preços do petróleo, a previsão de esgotamento nas próximas décadas, e os problemas de poluição, causados devido ao vasto uso dos combustíveis fósseis, têm resultado em uma crescente necessidade de desenvolver fontes de energias renováveis sem limites de duração e de menor impacto ambiental que os meios tradicionais existentes, estimulando, assim, recentes interesses na busca de fontes alternativas para combustíveis à base de petróleo (HAJJARI et al. 2017; CESAR, 2012).

A reciclagem de resíduos agrícolas e agroindustriais vem ganhando espaço cada vez maior, não simplesmente porque os resíduos representam "matérias primas" de baixo custo, mas, principalmente, porque os efeitos da degradação ambiental decorrente de atividades industriais e urbanas estão atingindo níveis cada vez mais alarmantes (ROSSI, 1999). De um modo geral, o aproveitamento integrado de resíduos gerados na indústria alimentícia pode evitar o encaminhamento destes aos aterros sanitários, permitindo o estabelecimento de novas alternativas empresariais e minimizando o impacto ambiental do acúmulo destes resíduos. Dentre os materiais que representam riscos de poluição ambiental e, por isso, merecem atenção especial, figuram os óleos vegetais usados, por exemplo, em processos de fritura por imersão.

Uma das alternativas para a reciclagem de óleos de fritura é a produção de biodiesel. De um modo geral, biodiesel foi definido pela National Biodiesel Board dos Estados Unidos como o derivado monoalquil éster de ácidos graxos de cadeia longa, proveniente de fontes renováveis como óleos vegetais ou gordura animal, cuja utilização está associada à substituição de combustíveis fósseis em motores de ignição por compressão (motores do ciclo Diesel) (FERRARI et al, 2005; FUKUDA et al, 2001; FURUTA et al, 2004). A Figura 1 descreve, esquematicamente, a produção do biodiesel por reação de transesterificação: 
Figura 1: Produção de ésteres metílicos e glicerol por transesterificação de triglicérides.

\begin{tabular}{|c|c|c|c|c|}
\hline $\mathrm{R}_{1} \mathrm{COOCH}_{2}$ & & $\mathrm{HOCH}_{2}$ & & ${ }_{1} \mathrm{COOCH}_{3}$ \\
\hline $\mathrm{OCH}+3 \mathrm{CH}_{3} \mathrm{OH}$ & $\stackrel{\text { catalisador }}{\rightleftharpoons}$ & $\mathrm{HOCH}$ & + & $\mathrm{R}_{2} \mathrm{COOCH}_{3}$ \\
\hline $\mathrm{R}_{3} \mathrm{COOCH}_{2}$ & & $\mathrm{HOCH}_{2}$ & & $\mathrm{R}_{3} \mathrm{COOCH}_{3}$ \\
\hline Triglicerídeo & & Glicerol & & biodiesel \\
\hline
\end{tabular}

Em 2005, o Congresso Nacional aprovou uma lei que torna obrigatória, a partir de 2007, a adição de biodiesel ao óleo diesel vendido no Brasil. A sua mistura ao diesel fóssil teve início em 2004, em caráter experimental e, entre 2005 e 2007, no teor de 2\%, a comercialização passou a ser voluntária. A obrigatoriedade veio no artigo $2^{\circ}$ da Lei $\mathrm{n}^{\circ} 11.097 / 2005$, que introduziu o biodiesel na matriz energética brasileira. Em janeiro de 2008, entrou em vigor a mistura legalmente obrigatória de $2 \%$ (B2), em todo o território nacional. Com o amadurecimento do mercado brasileiro, esse percentual foi sucessivamente ampliado até o atual percentual de 10,0\% (GOODWIN et al, 2005; ANP, 2016).

Uma alternativa possível ao combustível fóssil é o uso de óleos de origem vegetal, os quais podem ser denominados de "biodiesel" (HAJJARI et al. 2017; GERIS et al, 2007). O consumo de óleo de soja, por exemplo, vem crescendo cada vez mais, portanto será uma alternativa à transformação deste em biocombustível. O biodiesel apresenta vantagens potenciais em relação aos combustíveis fósseis principalmente no tocante da emissão de poluentes. O Quadro 01 apresenta esta comparação.

Quadro 1: Propriedades complementares atribuídas ao biodiesel em comparação ao óleo diesel comercial (RAMOS, 1999)

\begin{tabular}{lr}
\hline \multicolumn{1}{c}{ Características } & Propriedades Complementares \\
\hline $\begin{array}{l}\text { Características químicas } \\
\text { apropriadas }\end{array}$ & $\begin{array}{r}\text { Livre de enxofre e compostos aromáticos, alto número de cetanos, ponto } \\
\text { de combustão apropriado, excelente lubricidade, não tóxico e } \\
\text { biodegradável }\end{array}$ \\
$\begin{array}{l}\text { Ambientalmente } \\
\text { benéfico }\end{array}$ & $\begin{array}{c}\text { Nível de toxicidade compatível ao sal ordinário, com diluição tão rápida } \\
\text { quanto a do açúcar (Departamento de Agricultura dos Estados Unidos) } \\
\text { Reduz sensivelmente as emissões de (a) partículas de carbono (fumaça), } \\
\text { (b) monóxido de carbono, (c) óxidos sulfúricos e (d) hidrocarbonetos } \\
\text { policíclicos aromáticos }\end{array}$ \\
$\begin{array}{l}\text { Menos poluente } \\
\text { Economicamente } \\
\text { competitivo }\end{array}$ & $\begin{array}{c}\text { Complementa todas as novas tecnologias do diesel com desempenho } \\
\text { similar e sem a exigência da instalação de uma infraestrutura ou política } \\
\text { de treinamento }\end{array}$ \\
$\begin{array}{l}\text { Reduz aquecimento } \\
\text { global }\end{array}$ & $\begin{array}{c}\text { O gás carbônico liberado é absorvido pelas oleaginosas durante o } \\
\text { crescimento, o que equilibra o balanço negativo gerado pela emissão na } \\
\text { atmosfera }\end{array}$ \\
$\begin{array}{l}\text { Economicamente } \\
\text { atraente }\end{array}$ & $\begin{array}{c}\text { Permite a valorização de subprodutos de atividades agroindustriais, } \\
\text { aumento na arrecadação regional de ICMS, aumento da fixação do } \\
\text { homem no campo e de investimentos complementares em atividades } \\
\text { rurais }\end{array}$ \\
Regionalização & Pequenas e médias plantas para produção de biodiesel, podem ser
\end{tabular}


O Ifes (Instituto Federal de Educação, Ciência e Tecnologia do Espírito Santo), Campus Cachoeiro de Itapemirim está distante de Vitória, 130 $\mathrm{km}$; da cidade do Rio de Janeiro, 398 km, de Belo Horizonte, $490 \mathrm{~km}$. A principal atividade de Cachoeiro é o beneficiamento de pedras ornamentais, contando com aproximadamente 700 indústrias do ramo, conta também com uma atividade de comércio e serviços bem estruturada. Como a maioria das cidades brasileiras, não apresenta uma eficiente coleta e tratamento de esgoto, de forma que os resíduos provenientes

\section{MATERIAIS E MÉTODOS}

\section{Reagentes e Soluções Utilizadas}

Os reagentes e as soluções utilizadas na caracterização do material de partida (óleo residual produzido pela cantina do Ifes-Cachoeiro) foram: Ciclohexano PA (Dinâmica, 99,9\%), Etanol Anidro (Dinâmica, 99,9\%), Éter Etílico (Dinâmica, 99,9\%), Hidróxido de Potássio PA (Vetec, 99\%), Ácido Clorídrico (Vetec, 37,5\%), Solução iodo e cloro segundo Wijs (Dinâmica), Biftalato de potássio (Vetec, 99,9\%), Ácido Oléico (Vetec, 99,9\%), Sulfato de Sódio (Vetec, 99,9\%) e Carbonato de Sódio (Vetec, 99,9\%)

Obs: todas as soluções aquosas foram preparadas utilizando-se de água destilada.

\section{Transesterificação ou Obtenção dos ésteres etílicos}

A reação de transesterificação foi realizada em um sistema a temperatura de $25^{\circ} \mathrm{C}$. Foram adicionados em um balão, $50 \mathrm{~g}$ de óleo in natura/óleo residual e a solução contendo $0,8 \mathrm{~g}$ de catalisador $\mathrm{KOH}$ dissolvido em $206 \mathrm{~mL}$ de etanol anidro. Estabeleceu-se esse momento como da indústria, comércio e lares são despejados diretamente no Rio Itapemirim, um efluente que compõe a principal bacia hidrográfica da região. Sendo assim, este trabalho tem por objetivo produzir Biodiesel (éster etílico) por via catalítica, utilizando o óleo de soja usado em frituras da cantina do Ifes, Campus Cachoeiro de Itapemirim para uma possível aplicação no maquinário da instituição, diminuindo assim a emissão de resíduos e de consumo de combustíveis fósseis.

tempo zero da reação.

\section{Purificações da reação de transesterificação}

Após a separação das duas fases por decantação, os ésteres obtidos foram purificados através da lavagem com uma solução contendo água destilada e $25 \mathrm{~mL}$ de $\mathrm{HCl} 0,5 \%$ (v/v). Com isso o catalisador remanescente da reação foi neutralizado, fato confirmado com a análise da água de lavagem com indicador fenolftaleína a $1 \%$. A fase aquosa foi separada do éster por decantação e os traços de umidade foram eliminados pela filtração posterior com sulfato de sódio anidro.

\section{Determinações da Massa Específica}

A densidade $(\rho)$ do óleo residual foi medida em um densímetro Incoterm seguindo a norma ASTM D 4052, mantendo a temperatura com banho termostatizado Quimis.

\section{Determinações da Viscosidade Cinemática}

Os valores experimentais de viscosidade dinâmica $(\mu)$ foram determinados utilizando-se de 
viscosímetro tipo rotativo analógico, marca Quimis, na temperatura de $(40,0$ $\pm 0,1)^{\circ} \mathrm{C}$, mantida constante por um banho termostatizado marca Quimis. Conhecendo-se a massa específica, calculou-se a viscosidade cinemática ( $v)$ de acordo com a Equação 1:

$$
\nu=\mu / \rho(\text { Eq. 1) }
$$

\section{Determinações do Índice de Acidez (IA)}

A determinação do índice de acidez foi baseada no método descrito pelo Instituto Adolfo Lutz (2008). Para que essa determinação fosse realizada, pesou-se de 5,0 a $10 \mathrm{~g}$ da amostra em balança analítica diretamente em um erlenmeyer de $125,0 \mathrm{~mL}$, adicionou-se $25,0 \mathrm{~mL}$ de uma mistura éter/etanol (proporção 1:1) e 3 gotas de fenolftaleína. Titulou-se com hidróxido de potássio 0,01 mol. $\mathrm{L}^{-1}\left(f_{c}=0,84\right)$, padronizado com biftalato de potássio. $\mathrm{O}$ procedimento foi realizado em triplicata. Calcula-se o índice de acidez livre através da seguinte Equação 2:

$$
I A(m g K O H / g)=\frac{\left(V_{a}-V_{b}\right) \cdot 0,561 \cdot f_{c}}{m_{a}}
$$

(Eq. 2)

Onde:

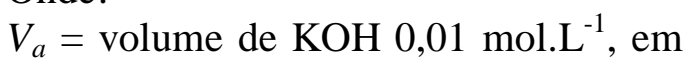
$\mathrm{mL}$

$V_{b}=$ volume de $\mathrm{KOH} 0,01$ mol. $\mathrm{L}^{-1}$ gasto para titular o "branco", em mL

$f_{c}=$ fator de correção para a concentração de KOH 0,01 mol.L ${ }^{-1}$.

\section{Determinações do Índice de Saponificação (IS)}

A determinação do índice de saponificação foi baseada no método descrito pelo Instituto Adolfo Lutz (2008). Para que essa determinação fosse realizada, pesou-se 4-5 $\mathrm{g}$ da amostra e adicionou-se $50 \mathrm{~mL}$ da solução alcoólica de $\mathrm{KOH} 4 \% \mathrm{~m} / \mathrm{v}$. Preparou-se um branco e mesmo tratamento, comporem sem a amostra. Conectou-se o condensador e deixou-se ebulir suavemente até a completa saponificação da amostra por 1 hora. Após o resfriamento do frasco, lavou-se a parte interna do condensador com água e titulou-se a amostra com uma solução padrão de $\mathrm{HCl} \quad 0,5 \mathrm{~mol} . \mathrm{L}^{-1}$, padronizado com carbonato de sódio $\left(f_{c}=1,14\right)$ na presença de fenolftaleína. Finalmente, calculou-se o índice de saponificação (IS) de acordo com a Equação 3 abaixo:

$$
I S(m g / g)=\frac{\left(V_{b}-V_{a}\right) \cdot 28,05 \cdot f_{c}}{m_{a}}
$$

(Eq. 3)

Onde:

$V_{a}=$ volume de $\mathrm{HCl} 0,50 \mathrm{~mol} \cdot \mathrm{L}^{-1}$, em $\mathrm{mL}$

$V_{b}=$ volume de $\mathrm{HCl} \quad 0,50 \mathrm{~mol} . \mathrm{L}^{-1}$ gasto para titular o "branco", em mL

$f_{c}=$ fator de correção para a concentração de $\mathrm{HCl}$ 0,5 mol. $\mathrm{L}^{-1}$

\section{Determinações do Índice de $\operatorname{Iodo}\left(\mathrm{II}_{2}\right)$}

$\mathrm{O}$ número de insaturações não tem apenas efeito nos valores de densidade e de viscosidade dos biodieseis, mas também é de grande importância na estabilidade oxidativa desse biocombustível. O método baseiase no tratamento da amostra com halogênios em excesso, que se adicionarão às duplas ligações. Os halogênios não reagidos são então titulados como tiossulfato de sódio (LOBO et al., 2009).

Pesou-se aproximadamente 0,25 g da amostra (óleo de soja comercial e o óleo residual) em frasco Erlenmeyer de $500 \mathrm{~mL}$ com tampa e adicionou-se 10 $\mathrm{mL}$ de ciclohexano (PA). Transferiu-se com auxílio de bureta, $25 \mathrm{~mL}$ de solução de Wijs no frasco Erlenmeyer. Tampou-se e agitou-se cuidadosamente com movimento de rotação, assegurando perfeita homogeneização. Deixou-se em repouso ao abrigo da luz 
e à temperatura ambiente, por 30 minutos. Adicionou-se $10 \mathrm{~mL}$ da solução de iodeto de potássio a $15 \%$ e $100 \mathrm{~mL}$ de água recentemente fervida e fria. Titulou-se com solução tiossulfato de sódio $0,1 \mathrm{~mol} . \mathrm{L}^{-1}$ até o aparecimento de uma fraca coloração amarela. Adicionou-se 1 a $2 \mathrm{~mL}$ de solução indicadora de amido $1 \%$ e continuou-se a titulação até o completo desaparecimento da cor azul. Preparouse uma determinação em branco e procedeu-se da mesma maneira que a amostra. De posse dos dados, calculouse o índice de Iodo $\left(I I_{2}\right)$ através da Equação 4, abaixo transcrita:

$$
I I_{2}\left(\% I_{2}\right)=\frac{\left(V_{b}-V_{a}\right) \cdot M \cdot 12,68}{m_{a}}
$$

(Eq. 4)

$V_{a}=$ volume de $\mathrm{Na}_{2} \mathrm{~S}_{2} \mathrm{O}_{3}$ gasto na titulação $(\mathrm{mL})$

$V_{b}=$ volume de $\mathrm{Na}_{2} \mathrm{~S}_{2} \mathrm{O}_{3}$ gasto para titular o "branco" (mL)

\section{RESULTADOS E DISCUSSÃO}

\section{Levantamentos de dados relacionados ao consumo de óleo de soja}

De acordo com um levantamento feito por Azevedo (2009), o número de residências registradas em Cachoeiro de Itapemirim-ES está em torno de 35.000 e, considerando que o número de latas de óleo de soja consumidas mensalmente por lar é de 3,21 unidades/mês, conclui-se que há uma geração de 94500 L de óleo comestível,
$M=$ concentração,

em mol.L ${ }^{-1}$ da solução de $\mathrm{Na}_{2} \mathrm{~S}_{2} \mathrm{O}_{3}$

$\mathrm{m}_{\mathrm{a}}=$ massa da amostra $(\mathrm{g})$

\section{Análise Qualitativa por Espectroscopia na Região UV-Visível}

A fim de se verificar possíveis mudanças na composição do óleo residual, após a reação de transesterificação, o material foi analisado qualitativamente, utilizandose um espectrofotômetro UV-Vis modelo Varian Cary 50, usando cubeta com caminho óptico de $1 \mathrm{~cm}$ na faixa de comprimento de onda de 190 a 1900nm. O material foi diluído em Ciclohexano 1:1000000 com auxílio de micropipeta. mensalmente (considerando que cada embalagem apresenta um conteúdo de 900 mL de óleo). Levando-se em conta o mesmo projeto, e observando os dados da Gráfico 1, são descartados $29 \%$ de resíduos lipídicos diretamente no ralo. Ainda, $39 \%$ do óleo usado é guardado em recipientes e/ou jogado no lixo, $11 \%$ são doados para instituições e $22 \%$ são utilizadas outras formas de descarte.

Gráfico 1: Formas de descarte do óleo residual por domicílios na cidade de Cachoeiro de Itapemirim-ES. (adaptado de AZEVEDO, 2009) 


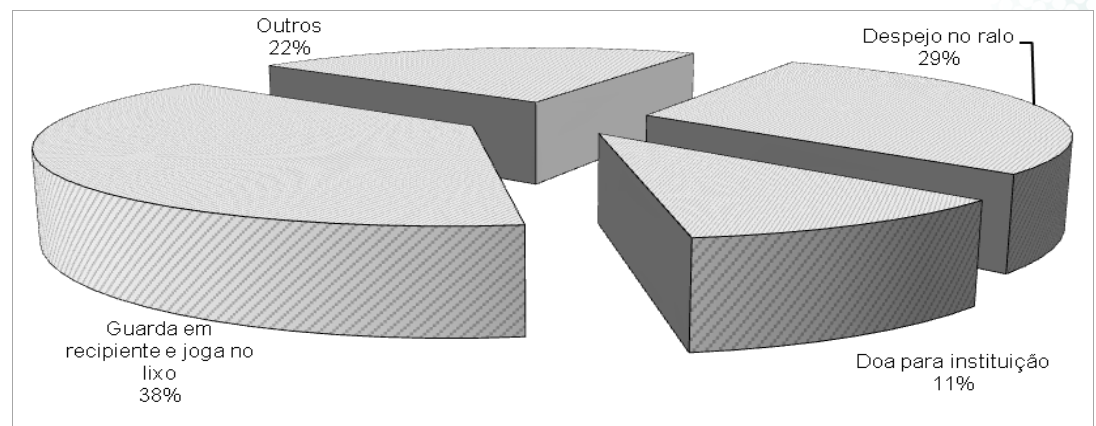

De maneira semelhante, o de óleo de soja pelo comércio de Gráfico 2 mostra o resultado do descarte Cachoeiro de Itapemirim.

Gráfico 2: Descarte de latas de óleo mensal pelo comércio da cidade de Cachoeiro de Itapemirim-ES. (adaptado de AZEVEDO, 2009).

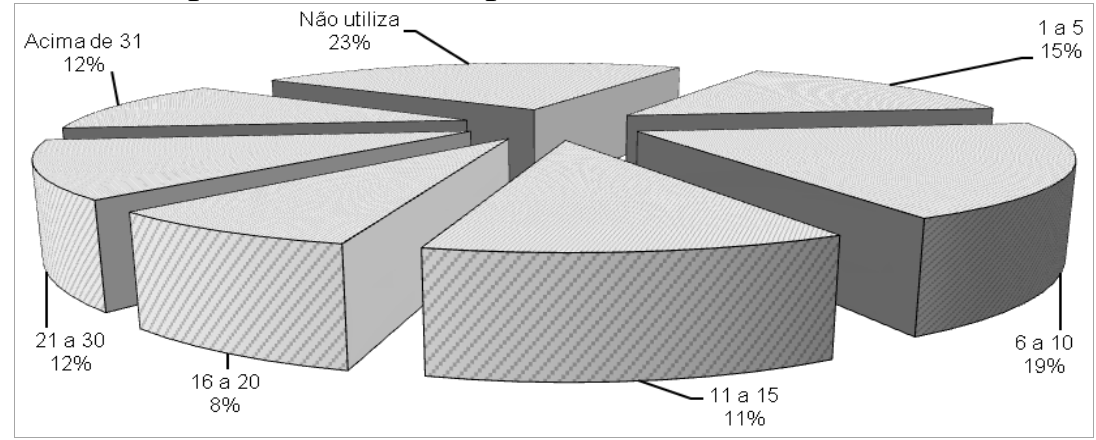

Segundo o Gráfico 2, cada empresa alimentícia de Cachoeiro de Itapemirim consome em média 14,41 unidades/mês de óleo comestível, o que representa um descarte cerca de cinco vezes maior, quando comparado com os domicílios. Isso se deve à utilização dessa matéria prima em restaurantes, lanchonetes e correlatos.

Neste sentido, o óleo, depois de usado, torna-se um resíduo indesejado e sua reciclagem como biocombustível alternativo não só retiraria do meio ambiente um poluente, mas também permitiria a geração de uma fonte alternativa de energia. Assim, duas necessidades básicas seriam atendidas de uma só vez. Uma solução possível para este descarte, seria a utilização do óleo residual para produção de biodiesel e, utilizada no transporte público da cidade, gerando assim economia e diminuição da emissão do resíduo para o Rio Itapemirim. A cantina do Campus do Ifes de Cachoeiro do Itapemirim utiliza óleo de soja com o objetivo de facilitar a transferência de calor para os alimentos, ou seja, utiliza-o para frituras de salgados e do almoço servido todos os dias para os alunos e funcionários do Campus. Com este projeto estimou que há uma produção média de $10.000 \mathrm{~mL}$ de óleo residual por mês, sendo verificado que, são despejados diretamente na pia, não passando por nenhum tratamento ou por acondicionamento e reciclagem. Por essa e por outras razões é interessante a realização do processo pelo qual se obtém do óleo de soja usado uma fonte renovável de energia.

\section{Reações de Transesterificação}

Neste trabalho, o processo de catálise básica foi adotado pelo fato de apresentar melhor rendimento $\mathrm{e}$ 
seletividade, além de menor tempo de reação que a catálise ácida, além de evitar problemas com corrosão dos componentes do motor, já que essas corrosões costumam ocorrer devido à presença de traços de ácido (SCHUCHARDT et al, 1998). O álcool utilizado foi o etanol (anidro) e em excesso, devido ao caráter reversível da reação de transesterificação (FERRARI et al., 2004). No nosso trabalho, o rendimento da reação foi de $84,71 \%$ para o biodiesel proveniente do óleo in natura e $81,39 \%$ no biodiesel proveniente do óleo residual. Após o término da reação observou-se a formação de uma fase superior correspondente aos ésteres etílicos e uma fase inferior contendo a glicerina, excesso de etanol, hidróxido de sódio que não reagiu, junto com os sabões formados durante a reação e alguns traços de ésteres etílicos e glicerídeos parciais.
A densidade do biodiesel está diretamente ligada com a sua estrutura molecular. Quanto maior o comprimento da cadeia carbônica do alquiléster, maior será a densidade, no entanto, esse valor decrescerá quanto maior for o número de insaturações presentes na molécula, pois menor será a interação entre as moléculas. A presença de impurezas também influenciará na densidade do biodiesel como, por exemplo, o álcool ou substâncias adulterantes (CRUZ et al., 2009). A diminuição da densidade também pode ser devido à diminuição da molécula orgânica, nesse caso substituiu-se o glicerol pelo etanol anidro.

No atual trabalho houve uma queda satisfatória na densidade após a reação de transesterificação, obedecendo aos parâmetros da ANP (Agência Nacional do Petróleo), segundo as Tabelas 1 e 2.

\section{Massa específica}

Tabela 1: Parâmetros físico-químicos analisados no material de partida (óleo residual/in natura) e os valores de referência para óleo de soja ANVISA (1999) e MIC (1985)

\begin{tabular}{ccccc}
\hline Característica & Unidade & $\begin{array}{c}\text { Valores de } \\
\text { Referência }\end{array}$ & Óleo Residual & $\begin{array}{c}\text { Óleo } \\
\text { soja In } \\
\text { Natura }\end{array}$ \\
\hline Massa específica a $20^{\circ} \mathrm{C}$ & $\mathrm{kg} / \mathrm{m}^{3}$ & $916-922^{\mathrm{a}}$ & 922 & 912 \\
Viscosidade Cinemática a $40^{\circ} \mathrm{C}$ & $\mathrm{cSt}$ & 36,8 & 36,6 & 32,5 \\
Índice de acidez & $\mathrm{mg} \mathrm{KOH} / \mathrm{g}$ & $<0,3^{\mathrm{b}}$ & 0,46 & 0,10 \\
Índice de Iodo & $\mathrm{g} \mathrm{I} / 100 \mathrm{~g}$ & $120-141$ & 89,38 & 112,34 \\
Índice de Saponificação & $\mathrm{mg} / \mathrm{g}$ & $180-200$ & 190,21 & 176,60 \\
Teste de umidade & $\mathrm{mg} / \mathrm{kg}$ & Anotar & 164,51 & 234,94 \\
& & & $(0,02 \%)$ & $(0,03 \%)$ \\
\hline
\end{tabular}

${ }^{\text {(a) }}$ medida na temperatura de $25^{\circ} \mathrm{C} ;{ }^{(b)}$ para óleo de soja refinado

Tabela 2: Parâmetros físico-químicos analisados no biodiesel (óleo residual / in natura) e os valores de referência Resolução ANP n ${ }^{\circ} 7$ (2008).

\begin{tabular}{ccccc}
\hline Características & Unidade & $\begin{array}{c}\text { Valores de } \\
\text { referência }\end{array}$ & Biodiesel Residual & $\begin{array}{c}\text { Biodiesel In } \\
\text { Natura }\end{array}$ \\
\hline Massa específica a $20^{\circ} \mathrm{C}$ & $\mathrm{kg} / \mathrm{m}^{3}$ & $850-900$ & 861 & 865 \\
Viscosidade Cinemática a $40^{\circ} \mathrm{C}$ & $\mathrm{mm}^{2} / \mathrm{s}$ & $3,0-6,0$ & 7,3 & 8,1 \\
Índice de acidez, máx. & $\mathrm{mg} \mathrm{KOH} / \mathrm{g}$ & 0,50 & 1,59 & 1,99 \\
Índice de Iodo & $\mathrm{g} / 100 \mathrm{~g}$ & Anotar & 83,99 & 114,02 \\
Índice de saponificação & $\mathrm{mg} / \mathrm{g}$ & Anotar & 207,85 & 211,51 \\
Teste de umidade & $\mathrm{mg} / \mathrm{kg}$ & 500 & 2838,41 & 3177,37 \\
& & & $(0,28 \%)$ & $(0,32 \%)$ \\
\hline
\end{tabular}


Após a reação de transesterificação, observou-se uma maior queda da densidade com o óleo residual (de $922 \mathrm{~kg} / \mathrm{m}^{3}$ para $861 \mathrm{~kg} / \mathrm{m}^{3}$ ) do que o óleo in natura, pela razão de o óleo residual apresentar, antes da reação, maior presença de impurezas. No entanto, ao comparar o valor da densidade do óleo residual $\left(922 \mathrm{~kg} / \mathrm{m}^{3}\right)$ com o valor do óleo in natura (912 $\mathrm{kg} / \mathrm{m}^{3}$ ), observa-se que, a densidade do primeiro é superior à do segundo. Este valor está coerente com os dados de índice de iodo, uma vez que ao observar o número de insaturações, vemos que a do óleo residual $\left(89,38 \mathrm{~g} \quad \mathrm{I}_{2} / 100 \mathrm{~g}\right)$ é inferior à do óleo in natura $(112,34 \mathrm{~g}$ $\mathrm{I}_{2} / 100 \mathrm{~g}$ ). Estes mostram que, o biodiesel gerado pelo óleo in natura apresentará maior interação entre suas moléculas.

Viscosidade

Viscosidade é a resistência apresentada por um fluido à alteração de sua forma ou aos movimentos internos de suas moléculas, umas em relação às outras. A viscosidade de um fluido indica sua resistência ao escoamento, sendo o inverso da viscosidade a fluidez. A viscosidade do biodiesel aumenta com o comprimento da cadeia carbônica e com o grau de saturação, e tem influência no processo de queima na câmara de combustão do motor. Alta viscosidade ocasiona heterogeneidade na combustão do biodiesel, devido à diminuição da eficiência de atomização na câmara de combustão, ocasionando a deposição de resíduos nas partes internas do motor. Os sabões residuais, bem como os glicerídeos não reagidos (mono-, di- e triglicerídeos), e os produtos da degradação oxidativa do biodiesel aumentam a viscosidadeda mistura. Esses contaminantes podem, portanto, ser monitorados indiretamente através da determinação da viscosidade (LOBO et al, 2009). Deste modo, farse-á o monitoramento da viscosidade antes e após a reação de transesterificação com o objetivo de se verificar mudança significativa dessa propriedade no material de partida.

Ao observar a viscosidade antes da reação vemos que o valor encontrado no óleo residual foi de 36,6 cSt, o que é muito próximo ao encontrado no óleo de soja 32,5 cSt. Esse pequeno aumento ocorre devido as impurezas presente no óleo residual.

Após a reação, apesar de diminuir consideravelmente, a viscosidade ficou acima do valor recomendo pela ANP. Supõe-se que seja devido a traços remanescentes da glicerina, fator principal da alta viscosidade no óleo de soja ou a presença de material de partida. Além disso, segundo o teste de umidade, observou-se umidade no biodiesel produzido. Este fator pode estar associado a formação de água pela reação do hidróxido de potássio com o álcool e, na presença do catalisador básico, poderá levar à hidrólise de algum éster produzido, com consequente formação de sabão. Essa saponificação indesejável reduz o rendimento do éster e dificulta consideravelmente a recuperação do glicerol, devido à formação de emulsão. Além disso, o consumo do catalisador reduz a eficiência da reação.

\section{Índice de acidez}

Os lipídios podem sofrer transformações químicas durante o armazenamento, no processamento ou, ainda, no uso como meio de transferência de calor (frituras, por exemplo). As transformações mais importantes são a rancidez hidrolítica, rancidez oxidativa e reversão. A rancidez, seja hidrolítica ou oxidativa, é a deterioração dos lipídios e constitui-se em um dos problemas técnicos mais importantes na indústria. Nesse caso, é muito importante a medida quantitativa dos ácidos graxos livres para que seja determinado o grau de deterioração. Outro efeito importante decorrente do 
aumento do teor de ácidos graxos livres é o abaixamento do ponto de fumaça do lipídio, com reflexos sobre a sua inflamabilidade (OSAWA et al., 2006). Entende-se então que quanto mais baixo for o índice de acidez maior será a qualidade da amostra. Ainda, índices de acidez e ácidos graxos livres influenciam na hidrólise do biodiesel e oxidação, quando em valores altos. Além disso, a acidez elevada pode catalisar reações intermoleculares dos triacilgliceróis, ao mesmo tempo em que afeta a estabilidade térmica do combustível na câmara de combustão. Também no caso do emprego carburante do óleo, a elevada acidez livre tem ação corrosiva sobre os componentes metálicos do motor. No caso do material de partida, recomendase que o óleo tenha baixos teores de ácidos graxos livres, pois nesse caso o catalisador alcalino será neutralizado, causando a saponificação (SCHUCHARD et al., 1998).

O valor encontrado para o óleo residual, antes da reação, foi $0,46 \mathrm{mg}$ $\mathrm{KOH} / \mathrm{g}$, com erro experimental de \pm $0,01 \mathrm{mg} \mathrm{KOH} / \mathrm{g}$. Esse é um valor adequado para transformação do óleo em biodiesel, visto que um excesso de ácidos graxos livres, quando são utilizados hidróxidos como catalisador, levaria a reações de saponificação, competindo com a reação de transesterificação. Após a transesterificação, houve um aumento no valor do índice de acidez que pode ser consequência da formação de ácidos graxos livres durante a reação, ou da presença de ácido clorídrico utilizado no processo de purificação.

\section{Índices de saponificação}

$\mathrm{O}$ índice de saponificação é a quantidade de base necessária para saponificar uma quantidade definida de amostra. Esse método é aplicável a todos os óleos e gorduras (INSTITUTO ADOLFO LUTZ, 2008). A sua determinação tem importância devido à relação entre o índice de saponificável e o comprimento da cadeia dos resíduos de ácidos graxos. Óleos e gorduras naturais - em sua maioria misturas de ésteres triglicerídeos de ácidos de cadeia longa - apresentam índices de saponificação semelhantes. Entretanto, a determinação do índice de saponificação é relevante como indício da presença de ácidos graxos contendo menos de 16 ou mais de 18 átomos de carbono, pelo fato de seu valor ser inversamente proporcional ao peso molecular médio dos ácidos graxos presentes na amostra (BARBOSA et al., 2009).

Segundo mostra a Tabela 1, o valor encontrado para o índice de saponificação foi $(190,21 \pm 8,48) \mathrm{mg} / \mathrm{g}$, um valor próximo do valor limite para o óleo de soja, indicando que o material de partida pode ter sofrido reações de hidrólise, liberando os ácidos graxos correspondentes, em consequência da utilização como líquido de transferência de calor para os alimentos (fritura). Essa interpretação é corroborada pelo incremento no índice de acidez em relação ao óleo de soja in natura em comparação com o óleo residual. Este último também foi medido neste trabalho, obtendo-se um valor de 0,10 $\mathrm{mg} \mathrm{KOH} / \mathrm{g}$ para o óleo in natura e 0,46 $\mathrm{mg} \mathrm{KOH} / \mathrm{g}$ para o óleo residual.

\section{Índices de Iodo}

Com o índice de iodo foi possível justificar o que se relaciona com as insaturações do material. $\mathrm{O}$ valor encontrado para o material de partida foi de $89,38 \mathrm{~g} \mathrm{I}_{2} / 100 \mathrm{~g}$. Esse valor indica que o óleo sofreu pouca degradabilidade, ora por termooxidação, ora por ataque de radicais livres em suas insaturações. Já o valor encontrado no óleo de soja in natura foi de $112,34 \mathrm{~g} \mathrm{I}_{2} / 100 \mathrm{~g}$. Esse resultado nos mostra que o óleo de soja in natura apresenta mais insaturações que o óleo 
residual. Quanto mais fortes forem as interações intermoleculares, maior será o tempo de escoamento e a densidade do líquido. A força das interações aumenta com o incremento da cadeia carbônica e diminui quanto maior for o grau de insaturação das moléculas que compõem o material. $\mathrm{O}$ éster do ácido linoléico, ácido graxo presente em grande quantidade no óleo de soja, possui duas insaturações, o que representa duas dobras na cadeia carbônica, fator que, juntamente com a presença do grupo funcional éster dificulta a aproximação das moléculas, tornando assim ainda mais fracas as interações de London.Portanto, o menor índice de iodo do óleo de soja in natura, quando comparado ao do óleo residual confirma o fato de a densidade e a viscosidade serem inferiores nesse último material. Após a realização da síntese os valores do teste de iodo quase não foram alterados, uma vez que com a síntese não se espera mudanças na quantidade e localização das insaturações.

\section{Espectroscopia na Região UV-Visível}

No Gráfico 3 abaixo, está referenciado o resultado da varredura, mostrando a faixa onde ocorreu absorção.

Gráfico 3: Espectro de absortividade na faixa do UV do óleo de fritura da cantina do Ifes-Cachoeiro, e do óleo de soja comercial diluídos em ciclohexano na proporção de $1: 1000$.

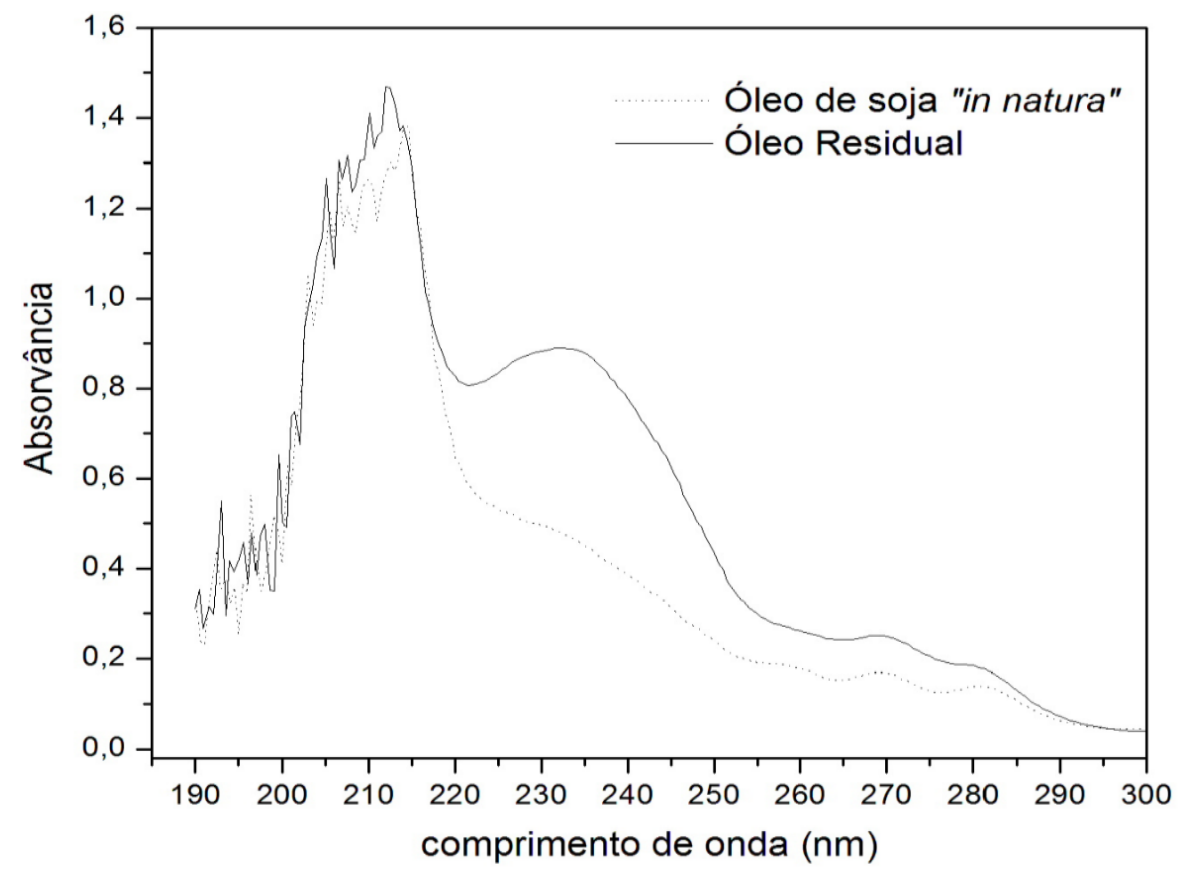

Observa-se através de um comparativo com o óleo de soja in natura o incremento da absorção da radiação ultravioleta no óleo residual na faixa que vai de $220 \mathrm{~nm}$ a $234 \mathrm{~nm}$. Esses valores estão associados à absorção $\pi \rightarrow \pi^{*}$ de dienos, que são compostos primários da oxidação. Durante a oxidação, os ésteres de ácidos graxos poli-insaturados contendo dieno ou polidienos apresentam uma alteração na posição de suas duplas ligações, resultado da isomerização e conjugação. Absorções a partir de $265 \mathrm{~nm}$ correspondem a compostos secundários da oxidação (trienos, aldeídos, cetonas) e é proporcional ao ganho de oxigênio e à formação de peróxidos durante os estágios iniciais de oxidação (SHAHIDI, 1995). Novamente, essas informações reforçam os resultados encontrados pelo índice de iodo, em que 
se verificou oxidação do material ou por radicais livres ou termo-oxidação.

$\mathrm{O}$ resultado da varredura antes da síntese, mostrado no Gráfico 4, indica a faixa onde ocorreu absorção.

Gráfico 4: Espectro de absortividade na faixa do UV do Biodiesel (residual/in natura) diluídos em Ciclohexano na proporção de 1:106 .

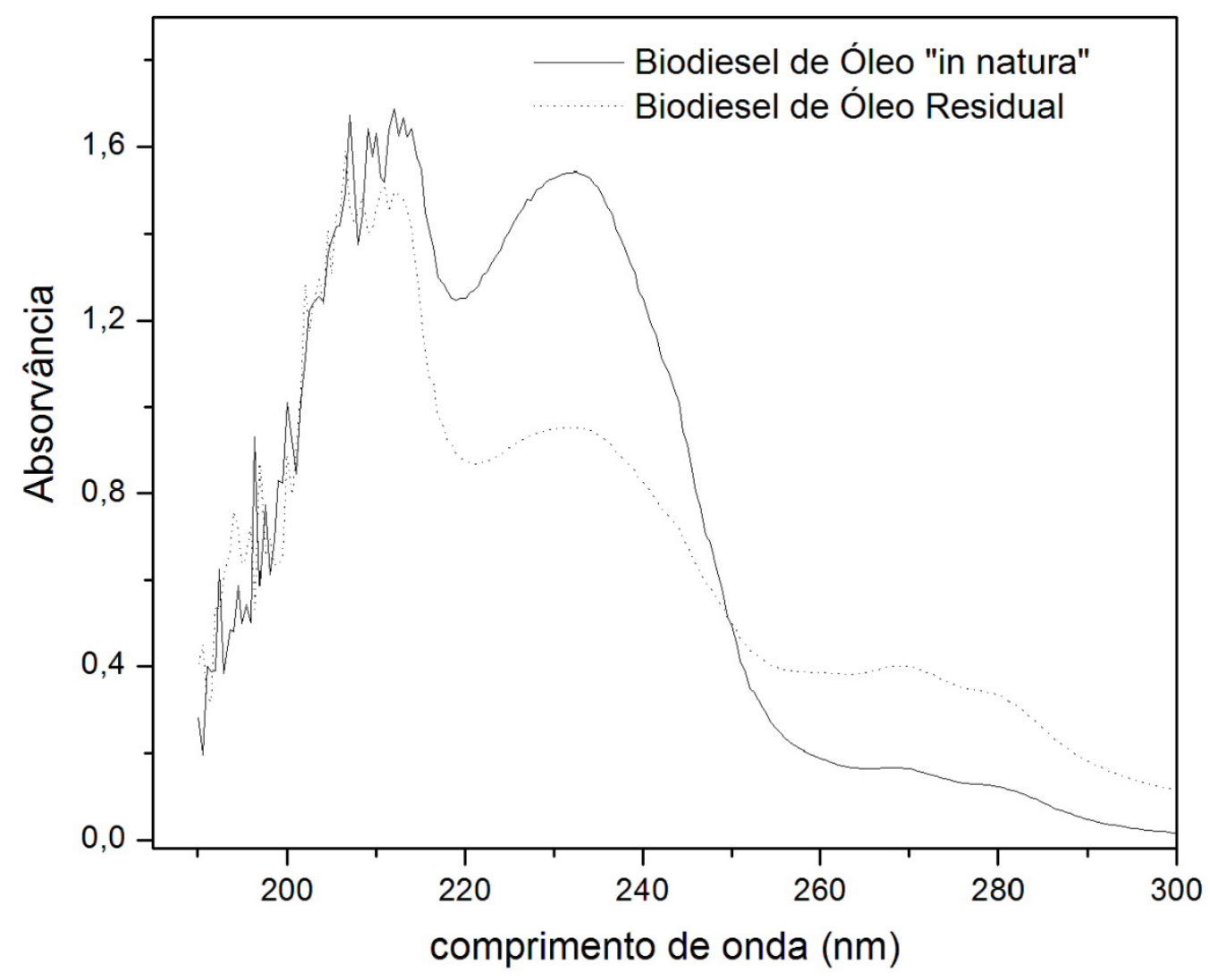

O Gráfico 5 mostra o do óleo residual antes e após a reação de comparativo de absorção da faixa UV transesterificação:

Gráfico 5: Espectro de absortividade na faixa do UV do Biodiesel de óleo residual diluídos em Ciclohexano na proporção de $1: 10^{6}$, antes e após a reação de transesterificação. 


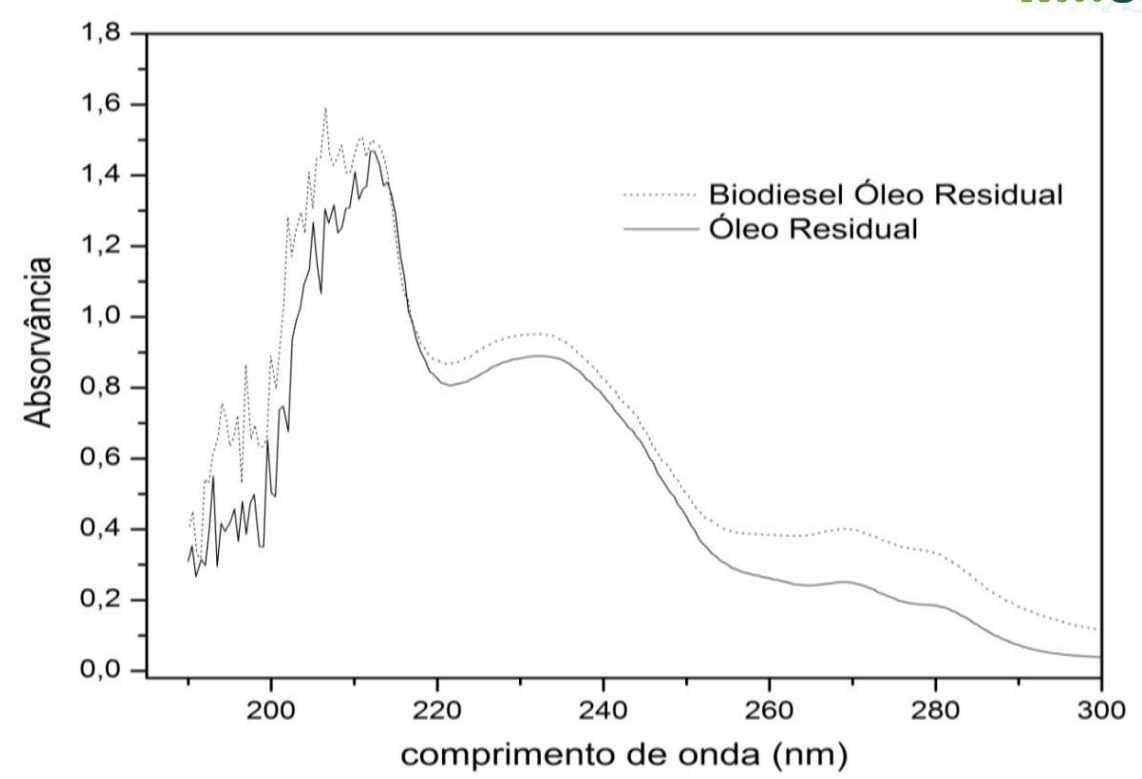

Ao fazer o comparativo com o espectro antes e após a síntese do biodiesel, percebe-se quase ou nenhuma alteração na absortividade na faixa que de $220 \mathrm{~nm}$ a $234 \mathrm{~nm}$, o que é comum. Afinal, com a realização da síntese não

\section{CONCLUSÕES}

O rendimento obtido na reação de esterificação foi de aproximadamente $80 \%$ com formação do subproduto (glicerol), importante material para formulação de cremes e loções na indústria de cosméticos. Além disso, a reação de transesterificação necessita de um álcool de cadeia curta, podendo ser utilizado etanol, um reagente abundante em nossa região.

Os dados físico-químicos obtidos no material de partida bem como no

\section{AGRADECIMENTOS}

Os autores deste trabalho agradecem ao Ifes pelo suporte necessário à execução dos experimentos.

\section{REFERÊNCIAS}

ANP, Biodiesel. Disponível em: http://www.anp.gov.br/biocombustiveis/bio é esperado modificação no números insaturações presentes na cadeia carbônica, fato comprovado pelo teste de Iodo.

biodiesel resultante mostram uma boa viabilidade na produção do combustível em escala piloto ou em escala industrial, porém, consideramos que o projeto se apresenta como sugestão para diminuição da poluição do Rio Itapemirim em pelo menos um dos parâmetros, no entanto, entendemos que ainda é necessário um aprofundamento na otimização da produção do biodiesel.

diesel. Acesso em: 06 out. 2019. 
AZEVEDO, O. de A.; RABBI, M. A. NETO, D. M. C.; HARTUIQ M. H. Fabricação de sabão a partir do óleo combustível residual: Conscientização e educação científica. In: Simpósio Nacional De Ensino De Física, 17, 2009, Vitória. Anais...

BARBOSA, B.S, et al . Aproveitamento do Óleo das Amêndoas de Tucumã do Amazonas na Produção de Biodiesel. Acta Amaz., v. 39, n.2, p. 371-376, 2009. http://dx.doi.org/10.1590/S004459672009000200015.

BRASIL. Ministério da Saúde. ANVISA. Resolução RE N 482 , de 23 de setembro de 1999.

CESAR, A.S., 2012. A competitividade da produção de biodiesel no Brasil: uma análise comparativa de mamona, dendê e soja. Dissertação. Engenharia de Produção. Universidade Federal de São Carlos, São Carlos, São Paulo, Brasil, p. 246p.

COSTA NETO, Pedro R. et al . Produção de biocombustível alternativo ao óleo diesel através da transesterificação de óleo de soja usado em frituras. Quím. Nova, São Paulo , v. 23, n. 4, p. 531-537. 2000 . http://dx.doi.org/10.1590/S010040422000000400017.

FERRARI, R.; A.; OLIVEIRA, V.; da S.; SCABIO, A. Biodiesel de soja- Taxa de Conversão em Ésteres Etílicos, Caracterização Físico-Química e Consumo em Gerador de Energia. Química Nova. v.28, p.19-23, 2005.

FUKUDA, H.; KONDO, A.; NODA, H.; Review- Biodiesel Fuel Production by transesterification of Oils. Journal of Bioscience and Bioengneering. 2001, v.92, n.5, p.405-416, 2001.

FURUTA, S.; ARATA, K.; MATSUHASHI, H. Biodiesel Fuel Production with Solid Superacid Catalysis in Fixed Bed Reactor under Atmospheric
Pressure. Catalysis Communications. v.5, p.721-723, 2004.

GERIS, R. et al. Biodiesel de Soja - Reação de Transesterificação para Aulas de Química Orgânica. Química Nova, v.30, n.5, p.1369-1773, 2007.

GOODWIN, Jr. et al. Syntesis of Biodiesel via Acid Catalysis. Ind. Eng. Chem. Res. v.44, p. 5353-5363, 2005.

HANNA, A.; M.; MA, F.; Biodiesel

Production a Review. Biosource

Tecnology, v.70, p.1-15, 1999.

INSTITUTO ADOLFO LUTZ. Métodos físico-químicos para análise de alimentos. São Paulo: Instituto Adolfo Lutz, 2008. Acesso em: 06/11/2019. Disponível em: https://wp.ufpel.edu.br/nutricaobromatologi a/files/2013/07/NormasADOLFOLUTZ.pdf

LOBO, I. P.; FERREIRA, S. L. C.; CRUZ, R. S. da. Biodiesel: parâmetros de qualidade e métodos analíticos. Quím. Nova. v.32, n.6, p. 1596-1608, 2009.

\section{MASOUMEH HAJJARI, MEISAM} TABATABAEI, MORTAZA AGHBASHLO, HOSSEIN GHANAVATI. A review on the prospects of sustainable biodiesel production: A global scenario with an emphasis on waste-oil biodiesel utilization, Renewable and Sustainable Energy Reviews, v.72, 2017, p. 445-464, https://doi.org/10.1016/j.rser.2017.01.034.

MINISTÉRIO DA INDÚSTRIA E DO COMÉRCIO, MIC; Óleos Vegetais Experiência de Uso Automotivo Desenvolvida pelo Programa OVEG I; Secretaria de Tecnologia Industrial; Coordenadoria de Informações Tecnológicas; Brasília, DF, 1985.

NATIONAL BIODIESEL BOARD; In: Anais do Congresso Internacional de Biocombustíveis Líquidos; Instituto de Tecnologia do Paraná; Secretaria de Estado da Ciência, Tecnologia e Ensino Superior; 
Curitiba, PR, 19 a 22 de julho, 1998; p. 42.

OSAWA,C. C; GONCALVES, L. A. G.; RAGAZZI, S. Titulação potenciométrica aplicada na determinação de ácidos graxos livres de óleos e gorduras comestíveis. Quím. Nova. v.29, n.3, p. 593-599, 2006.

RAMOS, L. P.; In: Anais Do Congresso Brasileiro De Soja; Centro Nacional De Pesquisa De Soja; Empresa Nacional de Pesquisa Agropecuária; Londrina, PR, 17 a 20 de maio, 1999; p. 233.

SCHUCHARDT, U.; SERCHELI, R.;

VARGAS, M.; R.; Transesterification of Vegetable Oils: a Review. J. Braz. Chem. Soc., v.9, 199-210, 1998.

SHAHIDI, F. Stability of fats and oils. In: Latin American Congress And Exhibit On Fats And Oils Processings, 6., Campinas, 1995. Proceedings. Campinas: Sociedade Brasileira de Óleos e Gorduras, 1995. 